\title{
Redrawing the Map to Novel DILI Biomarkers in Circulation: Where Are We, Where Should We Go, and How Can We Get There?
}

\author{
Joel H. Vazquez ${ }^{1}$ and Mitchell R. McGill ${ }^{1,2, *(D)}$ \\ 1 Department of Pharmacology and Toxicology, College of Medicine, University of Arkansas for Medical \\ Sciences, Little Rock, AR 72212, USA; jvazquez@uams.edu \\ 2 Department of Environmental and Occupational Health, Fay W. Boozman College of Public Health, \\ University of Arkansas for Medical Sciences, Little Rock, AR 72212, USA \\ * Correspondence: mmcgill@uams.edu; Tel.: +1-501-526-6696
}

Citation: Vazquez, J.H.; McGill, M.R. Redrawing the Map to Novel DILI Biomarkers in Circulation: Where Are We, Where Should We Go, and How Can We Get There? Livers 2021, 1, 286-293. https://doi.org/10.3390/ livers1040022

Academic Editor:

Anup Ramachandran

Received: 28 October 2021

Accepted: 25 November 2021

Published: 1 December 2021

Publisher's Note: MDPI stays neutral with regard to jurisdictional claims in published maps and institutional affiliations.

Copyright: (C) 2021 by the authors. Licensee MDPI, Basel, Switzerland. This article is an open access article distributed under the terms and conditions of the Creative Commons Attribution (CC BY) license (https:// creativecommons.org/licenses/by/ $4.0 /)$.

\begin{abstract}
Circulating biomarkers of drug-induced liver injury (DILI) have been a focus of research in hepatology over the last decade, and several novel DILI biomarkers that hold promise for certain applications have been identified. For example, glutamate dehydrogenase holds promise as a specific biomarker of liver injury in patients with concomitant muscle damage. It may also be a specific indicator of mitochondrial damage. In addition, microRNA-122 is sensitive for early detection of liver injury in acetaminophen overdose patients. However, recent events in the field of DILI biomarker research have provided us with an opportunity to step back, consider how biomarker discovery has been done thus far, and determine how to move forward in a way that will optimize the discovery process. This is important because major challenges remain in the DILI field and related areas that could be overcome in part by new biomarkers. In this short review, we briefly describe recent progress in DILI biomarker discovery and development, identify current needs, and suggest a general approach to move forward.
\end{abstract}

Keywords: hepatotoxicity; drug-induced liver injury; acute liver failure; diagnosis; prognosis; regulation

\section{Introduction}

Liver injury is a life-threatening adverse effect of some drugs. In fact, drug-induced liver injury (DILI) is one of the most common reasons for pre-approval termination of new drugs and for post-approval withdrawal. There are two basic forms of DILI: intrinsic and idiosyncratic. Intrinsic DILI is caused solely by physico-chemical properties (e.g., reactivity) that are intrinsic to the drug itself (or to a metabolite) and usually displays a clear dose-response as a result. Idiosyncratic DILI (usually abbreviated IDILI), on the other hand, depends in part upon "host" factors (e.g., poor immunotolerance) and has much weaker dose-response, and therefore poor predictability as a result. Clinically, intrinsic DILI and IDILI together make up the primary cause of acute liver failure (ALF) in the US [1]. From a regulatory point of view, IDILI is also notoriously difficult to predict or diagnose. As a result, regulatory agencies and clinicians err on the side of caution, adopting an approach based on monitoring of circulating alanine aminotransferase (ALT) and other conventional liver markers within the context of the greater clinical picture. However, weaknesses in that approach are increasingly clear. To address that, recent years have seen considerable effort invested in development of novel circulating biomarkers of liver injury.

In 2018-2019, DILI biomarker researchers were shaken by the revelation that a prominent investigator committed scientific misconduct [2]. Although investigation revealed the impropriety was limited to one individual and one analyte, the consequences are far-reaching. For example, the European Medicines Agency retracted a letter of support for development of several DILI biomarkers for regulatory use. We view this as an opportunity to evaluate where we are in the field, how we got here, and how we can move forward in a 
way that optimizes the biomarker discovery process and reduces potential bias. Here, we discuss current DILI biomarkers and then look to the future to identify areas of continued need and general approaches to meet those needs.

\section{Points of Departure}

\subsection{Where Are We?}

Many interesting liver injury biomarkers have been identified, including keratin 18 (K18), caspase-cleaved K18 (ccK18), high-mobility group box 1 protein (HMGB1), microRNA-122 (miR-122), glutamate dehydrogenase (GLDH), osteopontin (OPN), macrophage colony-stimulating factor receptor (MCSFR), and numerous others [3-11]. Some clearly show promise for specific applications. For example, some provide mechanistic insight: ccK18 indicates mode of cell death (apoptosis vs. necrosis) [3]; MCSFR may indicate inflammation [9]; GLDH, mitochondrial DNA, carbamoyl phosphate synthetase 1 and acylcarnitines may indicate mitochondrial damage [5,12-15]; OPN, alpha-fetoprotein (AFP), and others reflect regeneration $[9,16]$. Others have clinical benefits: miR-122 seems to predict later liver injury in early-presenting acetaminophen (APAP) overdose patients [8], while GLDH is helpful to distinguish liver and muscle damage in patients at risk of both $[9,17]$. Indeed, the Critical Path Institute and associated researchers are making great strides to promote the widespread adoption of GLDH as a liver injury biomarker in the context of clinical trials to test treatments for musculoskeletal disorders. However, these successes have largely been achieved by adopting biomarkers developed for other diseases and therefore often lacking specificity. To some degree, there have also been developments of convenience-being tested only after introduction of simple, commercially-available test kits. It is tempting to imagine the great strides that could be made with more focused, systematic efforts beginning with untargeted 'omics or modern artificial intelligence methods.

\subsection{How Did We Get Here?}

So far, despite the achievements listed above, the process of discovery of novel liver injury biomarkers has proceeded more-or-less laissez-faire. Biomarkers intended for use in other diseases have been co-opted for liver injury. For example, ccK18 was originally described as an immunocytochemical marker of apoptosis in cancer cells [18]. ELISAs were then developed and used to test it as a circulating biomarker of cancer $[19,20]$. Years passed between the identification of ccK18 as an apoptosis marker in cells and the first application in liver injury patients, and then the earliest studies focused on chronic liver diseases [21,22]. It is immediately clear from the history that ccK18 and K18 are not specific for the liver and certainly not for DILI. Similarly, HMGB1 was first measured in serum from sepsis patients [23] and later characterized as a damage-associated molecular pattern released from various cell types after necrosis [24], before being applied to liver injury. Those biomarkers became popular and were applied to liver injury only after introduction of convenient methods (e.g., commercial ELISAs) to measure them. For other biomarkers, such as malate dehydrogenase, convenient measurement methods have already existed for decades, but those markers have been tested and found to be elevated in numerous contexts, not just liver injury. Even ALT, the clinical and regulatory gold-standard for detection of liver injury, was intended as a biomarker of myocardial damage [25,26]. In fact, among the current crop of DILI biomarkers, only miR-122 was discovered systematically with a focus on liver damage [27], and even miR-122 has somewhat limited specificity, for example, being elevated in metabolic diseases and renal cell carcinoma as well $[28,29]$. Limiting biomarker exploration to biomarkers identified in other contexts and/or that have convenient test methods immediately limits the specificity for DILI and fails to optimize sensitivity. In addition, there may be more pressure to report positive results when only a small number of potential biomarkers and test methods are available. 


\subsection{How Should We Move Forward?}

We contend that more systematic approaches are needed to fill the gaps in DILI biomarker development. Experiments should be designed to meet specific needs in the DILI field, moving forward from the need to the biomarker and not vice versa. This could be coupled with untargeted measurements for advanced, unbiased, 'omics- or artificial intelligence-based approaches for the identification of many novel biomarkers, as recently discussed in detail elsewhere [30]. Those results should then be validated in additional models and in humans using appropriate samples.

\section{DILI Destinations}

So, what are the current needs? It has been argued that biomarkers could be useful for (1) diagnosis of DILI due to any drugs; (2) prediction of IDILI, specifically, prior to drug use; (3) prognosis in intrinsic DILI, IDILI, and acute liver injury more generally; and (4) prediction of hepatotoxic liability during pre-clinical drug development and early clinical trials. Here, we evaluate each and identify specific approaches that may work. We also argue that two of these goals are especially important and realistically achievable.

\subsection{Biomarkers for Diagnosis}

Clinically, recent reports have noted that diagnosis of DILI is challenging due to low prevalence [10,31-33]. It is unlikely that a biomarker can be developed that will reliably rule-in IDILI because the low prevalence (typically $\leq 1 \%$ and often as low as $\leq 0.1 \%$ ) of IDILI among users of any given IDILI-causing drug means that no biomarker can achieve sufficient positive post-test probability (or positive predictive value) to prove a diagnosis (Figure 1) [31,33]. For the typical range of IDILI incidence, positive post-test probability maxes out around $10 \%$, even for a test with high clinical sensitivity and specificity (Figure 1). Although high negative post-test probability (and negative predictive value) can certainly be achieved (solid line in Figure 1B), the pre-test probability of IDILI is already low due to low prevalence, so a negative test result would have questionable benefit. However, it may be possible to diagnose causes of intrinsic DILI. Indeed, serum APAP-protein adducts appear to be useful to diagnose APAP overdose [33,34], which is the most common cause of DILI overall. Unfortunately, because other drugs are less common causes of liver injury individually, it is not clear how well this approach would actually work beyond APAP, especially in the case of IDILI-causing drugs.

A

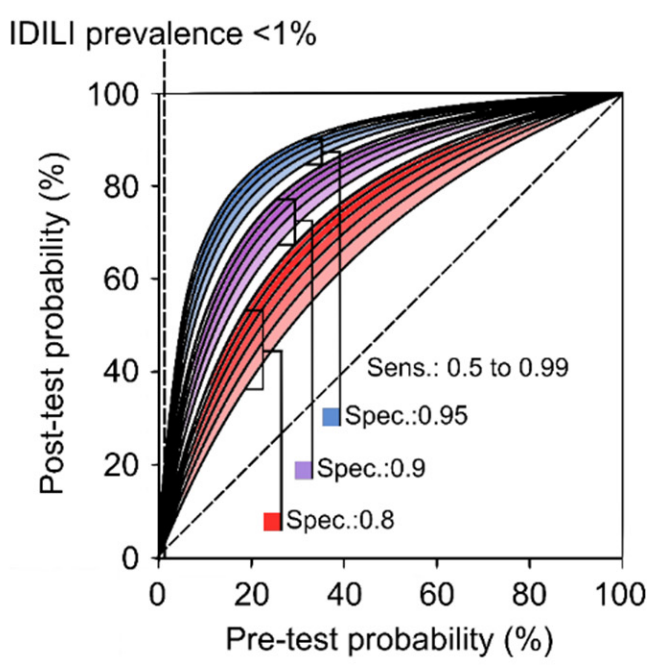

$\mathrm{B}$

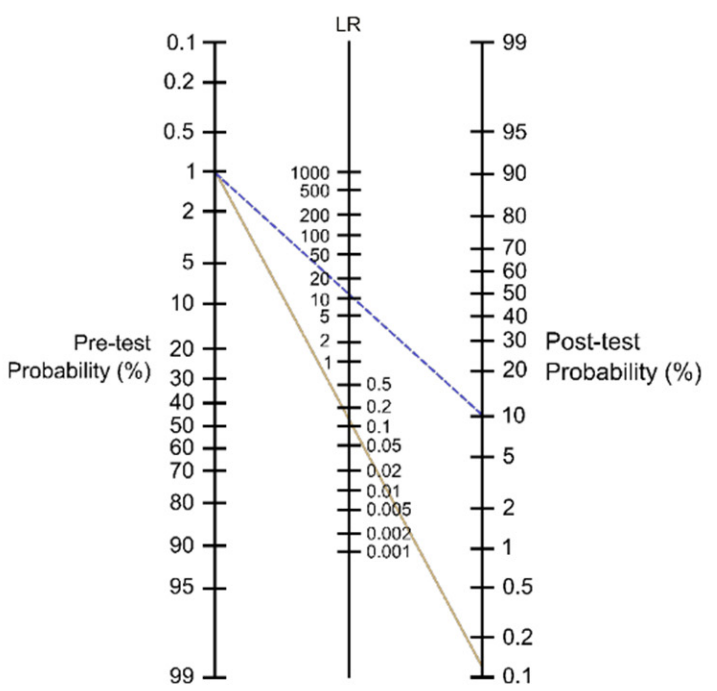

Figure 1. Relationship of test performance and pre-test probability to post-test probability. (A) Prevalence (pre-test probability) is shown on the $x$-axis. Post-test probability is shown on the $y$-axis. Each line displays the post-test probability 
on the $y$-axis as a function of prevalence (pre-test probability) at ascending test sensitivity $(50 \%, 60 \%, 70 \%, 80 \%, 90 \%$ and $99 \%$ ) and at fixed values for test specificity of $80 \%$ (red series), $90 \%$ (purple series), and $95 \%$ (blue series). The vertical line shows a typical upper limit of IDILI prevalence. (B) Fagan nomogram displaying prevalence (pre-test probability) on the left, likelihood ratio (LR) in the middle, and post-test probability on the right. The dashed blue line shows the relationship with positive post-test probability for a biomarker that has $>90 \%$ sensitivity and $>90 \%$ specificity for DILI (LR+ $=9-10)$. The solid yellow line shows the relationship with negative post-test probability for a biomarker that has $90 \%$ sensitivity and $90 \%$ specificity for DILI (LR $-=0.11)$.

\subsection{Biomarkers for Prediction}

Many researchers have proposed that genetic and circulating biomarkers for prediction could be used to manage risk of IDILI, specifically, by determining the likelihood that a drug will cause injury before a patient takes it. Numerous gene variants are associated with IDILI [35], but currently only one is used clinically for this purpose. The link between HLA B $* 5701$ and abacavir reactions is useful because $\sim 5 \%$ of abacavir users experience an adverse event, which can include IDILI $[33,36]$. It is unlikely that many other biomarkers will gain purchase for prediction of IDILI for the same reason it is difficult to diagnose IDILI. The prevalence of liver injury among users of most IDILI-associated drugs is low, usually $\leq 1 \%$ and often even $\leq 0.1 \%$. Thus, even for a very good theoretical biomarker with $95 \%$ clinical specificity for IDILI, the rate of false positives will always be much greater than the rate of true positives, resulting in very low positive predictive value or positive post-test probability (Figure 1). Although it is theoretically possible to predict IDILI in the case of drugs with relatively high incidence of injury (e.g., ximelagatran [32,33]) or for drugs with high prevalence of adverse events in general-not limited to liver damage (like abacavir) - those examples are relatively rare. In addition, most genetic associations with IDILI are somewhat weak, reducing their clinical specificity in the first place.

\subsection{Biomarkers for Prognosis}

Biomarkers for prognosis in DILI overall (whether intrinsic or idiosyncratic) are sorely needed; first, to predict development of injury in patients presenting with normal-to-low ALT values, and second, to predict death in patients with drug-induced ALF. Recent studies have demonstrated that several biomarkers, but especially miR-122, can predict later injury in early-presenting APAP overdose patients despite its considerable biological variation [8]. In fact, miR-122 is probably approaching the limit of what is possible in that respect, based on the prevalence of injury among those who present early with suspected APAP overdose [33]. However, we lack biomarkers to predict death after acute liver injury, and particularly ALF. ALF has high mortality ( $\geq 25 \%$ ) [37-39] and availability of transplantable livers is limited. Biomarkers to predict death could greatly improve clinical decision-making by helping physicians determine which patients need a new liver to survive. Theoretically, it should be easy to identify biomarkers for death in ALF that have high predictive values due to the high pre-test probability of death in ALF. However, less effort has been directed this way compared to other areas of DILI biomarker research. Still, some interesting results are available. For example, circulating AFP predicts survival in ALF, though it changes late in the course of ALF when it may be too late for a liver transplant [16]. Recent data indicate that OPN and K18 could also be useful to predict mortality [9], and a recent systematic review indicated that the combination of K18 with other measures may be especially helpful [40], though additional studies need to validate these early results. In addition, biomarkers that may reflect the severity or extent of underlying injury may be promising for prognostic use, as worse injury may be expected to lead to worse outcomes. Some recent examples of such biomarkers include advanced oxidation protein products and ischemia-modified albumin, which are elevated in DILI patients [41]. Overall, considerably more work should be done in this area. 


\subsection{Biomarkers for Hepatotoxic Liability}

Better safety biomarkers for regulation are also still needed. The current practice of screening for hepatotoxicity with ALT and other conventional markers during clinical trials comes from the basic principles Hy's Law and Temple's Corollary. In essence, Hy's Law states that an elevation in ALT accompanied by jaundice is a signal of serious liver injury, while Temple's Corollary states that a drug that causes modest, transient ALT elevations in many patients is likely to cause Hy's Law cases in at least a few. Thus, moderate ALT elevations in more than one subject or mild elevation of both ALT and bilirubin in even a single subject are considered signs of potentially serious hepatocellular damage that warrant termination of new drugs.

A problem with using ALT in this way is that it lacks specificity for DILI, but in different contexts. Pre-clinical models have poor sensitivity to predict IDILI in humans [41], while the modest ALT elevations frequently observed in clinical trials are sensitive but lack specificity for severe injury. The US FDA acknowledges that some drugs meet the criteria for hepatotoxicity concern in clinical testing, but have never caused a case of severe DILI in the general population [42]. Indeed, many drugs such as APAP, heparins, and cholestyramine can cause non-progressive ALT elevations in many users with no other evidence of liver damage [43-50]. Furthermore, there is evidence that ALT lacks specificity for any tissue damage, be it in the liver or elsewhere, in certain diseases [51,52]. We recently tried to address this issue by combining models of benign serum ALT elevations and models of liver injury with untargeted proteomics to identify serum biomarkers that can differentiate between them [52]. We propose that such a biomarker could be used in an algorithmic "screen-and-confirm" approach to determine if minor ALT elevations detected during screening for injury in clinical trials reflect actual liver injury. As for improving the sensitivity of pre-clinical models, one interesting strategy attempted was to compare serum biomarkers between animals treated with pairs of drugs with similar pharmacology, one of which was known to cause DILI in humans and one of which was not $[53,54]$. Those studies succeeded in identifying analytes that may be specific for the DILI-causing drugs, demonstrating that such an approach has promise.

Overall, the areas of greatest need and potential for further biomarker development now appear to be biomarkers of prognosis to predict death in DILI-related ALF (and ALF more generally) and biomarkers for hepatotoxic liability during drug development. There is potential for additional developments in the areas of diagnosis and prediction as well, but the issue of low prevalence will be a major hurdle to overcome.

\section{Conclusions}

We have an opportunity to re-examine the DILI biomarker field and consider how to move forward. Continued progress is important because significant needs remain. Biomarkers of diagnosis and prediction are theoretically possible and could have major clinical value, but will be very challenging to develop. On the other hand, biomarkers are urgently needed to predict patient outcomes in DILI, and especially DILI-induced ALF, and should be relatively simple to develop. Furthermore, biomarkers that are specific for liver injury are needed to determine if modest ALT elevations observed in clinical trials or clinical practice reflect actual liver injury, and we suggest using them in a screen-andconfirm approach. Finally, regardless of the focus, more systematic approaches such as applying 'omics methods to specific models of liver injury or to samples from patients could help us meet these needs in a less biased way.

Author Contributions: Conceptualization, M.R.M. and J.H.V.; methodology, M.R.M. and J.H.V.; investigation, M.R.M. and J.H.V.; resources, M.R.M.; data curation, M.R.M. and J.H.V.; writingoriginal draft preparation, J.H.V.; writing—review and editing, M.R.M.; visualization, M.R.M.; supervision, M.R.M.; project administration, M.R.M.; funding acquisition, M.R.M. All authors have read and agreed to the published version of the manuscript. 
Funding: This research was funded by the AASLD Foundation (2018 Pinnacle Research Award) and by the US National Institutes of Health (T32 GM106999).

Institutional Review Board Statement: Not applicable.

Informed Consent Statement: Not applicable.

Data Availability Statement: Not applicable.

Conflicts of Interest: M.R.M. consults for Acetaminophen Toxicity Diagnostics, LLC and GlaxoSmithKline.

\section{References}

1. Lee, W.M. Acute Liver Failure. Semin. Respir. Crit. Care Med. 2012, 33, 36-45. [CrossRef]

2. Mezzapelle, R.; Venereau, E.; Bianchi, M.E. Stress and Alarmins. Report from the 9th iD\&EAs meeting. Cell Death Dis. 2019, 10, 1-3. [CrossRef]

3. Craig, D.G.N.; Lee, P.; Pryde, E.A.; Masterton, G.S.; Hayes, P.C.; Simpson, K.J. Circulating apoptotic and necrotic cell death markers in patients with acute liver injury. Liver Int. 2011, 31, 1127-1136. [CrossRef] [PubMed]

4. Schomaker, S.; Warner, R.; Bock, J.; Johnson, K.; Potter, D.; Van Winkle, J.; Aubrecht, J. Assessment of Emerging Biomarkers of Liver Injury in Human Subjects. Toxicol. Sci. 2013, 132, 276-283. [CrossRef] [PubMed]

5. McGill, M.; Sharpe, M.R.; Williams, C.D.; Taha, M.; Curry, S.C.; Jaeschke, H. The mechanism underlying acetaminophen-induced hepatotoxicity in humans and mice involves mitochondrial damage and nuclear DNA fragmentation. J. Clin. Investig. 2012, 122, 1574-1583. [CrossRef] [PubMed]

6. McGill, M.R.; Staggs, V.S.; Sharpe, M.R.; Lee, W.M.; Jaeschke, H. Acute Liver Failure Study Group Serum mitochondrial biomarkers and damage-associated molecular patterns are higher in acetaminophen overdose patients with poor outcome. Hepatology 2014, 60, 1336-1345. [CrossRef]

7. Weemhoff, J.L.; Woolbright, B.L.; Jenkins, R.E.; McGill, M.; Sharpe, M.R.; Olson, J.C.; Antoine, D.J.; Curry, S.C.; Jaeschke, H. Plasma biomarkers to study mechanisms of liver injury in patients with hypoxic hepatitis. Liver Int. 2017, 37, 377-384. [CrossRef] [PubMed]

8. Dear, J.W.; Clarke, J.I.; Francis, B.; Allen, L.; Wraight, J.; Shen, J.; Dargan, P.; Wood, D.; Cooper, J.; Thomas, S.H.L.; et al. Risk stratification after paracetamol overdose using mechanistic biomarkers: Results from two prospective cohort studies. Lancet Gastroenterol. Hepatol. 2018, 3, 104-113. [CrossRef]

9. Church, R.J.; Kullak-Ublick, G.A.; Aubrecht, J.; Bonkovsky, H.L.; Chalasani, N.; Fontana, R.J.; Goepfert, J.C.; Hackman, F.; King, N.M.P.; Kirby, S.; et al. Candidate biomarkers for the diagnosis and prognosis of drug-induced liver injury: An international collaborative effort. Hepatology 2019, 69, 760-773. [CrossRef]

10. McGill, M.; Jaeschke, H. Biomarkers of drug-induced liver injury: Progress and utility in research, medicine, and regulation. Expert Rev. Mol. Diagn. 2018, 18, 797-807. [CrossRef]

11. Andrade, R.J.; Chalasani, N.; Björnsson, E.S.; Suzuki, A.; Kullak-Ublick, G.A.; Watkins, P.B.; Devarbhavi, H.; Merz, M.; Lucena, M.I.; Kaplowitz, N.; et al. Drug-induced liver injury. Nat. Rev. Dis. Prim. 2019, 5, 1-22. [CrossRef]

12. McGill, M.; Li, F.; Sharpe, M.R.; Williams, C.D.; Curry, S.C.; Ma, X.; Jaeschke, H. Circulating acylcarnitines as biomarkers of mitochondrial dysfunction after acetaminophen overdose in mice and humans. Arch. Toxicol. 2013, 88, 391-401. [CrossRef]

13. Bhattacharyya, S.; Yan, K.; Pence, L.; Simpson, P.M.; Gill, P.; Letzig, L.G.; Beger, R.D.; E Sullivan, J.; Kearns, G.L.; Reed, M.D.; et al. Targeted liquid chromatography-mass spectrometry analysis of serum acylcarnitines in acetaminophen toxicity in children. Biomark. Med. 2014, 8, 147-159. [CrossRef] [PubMed]

14. Weerasinghe, S.V.W.; Jang, Y.-J.; Fontana, R.J.; Omary, M.B. Carbamoyl phosphate synthetase-1 is a rapid turnover biomarker in mouse and human acute liver injury. Am. J. Physiol. Gastrointest. Liver Physiol. 2014, 307, G355-G364. [CrossRef] [PubMed]

15. McGill, M.R.; Jaeschke, H. Biomarkers of mitotoxicity after acute liver injury: Further insights into the interpretation of glutamate dehydrogenase. J. Clin. Transl. Res. 2021, 7, 61-65. [CrossRef]

16. Schmidt, L.E.; Dalhoff, K. Alpha-fetoprotein is a predictor of outcome in acetaminophen-induced liver injury. Hepatology 2005, 41, 26-31. [CrossRef]

17. Schomaker, S.; Potter, D.; Warner, R.; Larkindale, J.; King, N.; Porter, A.C.; Owens, J.; Tomlinson, L.; Sauer, J.-M.; Johnson, K.; et al. Serum glutamate dehydrogenase activity enables early detection of liver injury in subjects with underlying muscle impairments. PLoS ONE 2020, 15, e0229753. [CrossRef]

18. Leers, M.P.G.; Bergman, T.; Tribbick, G.; Persson, B.; Ramaekers, F.C.S.; Nap, M.; Schutte, B. Immunocytochemical detection and mapping of a cytokeratin 18 neo-epitope exposed during early apoptosis. J. Pathol. 1999, 187, 567-572. [CrossRef]

19. Ueno, T.; Toi, M.; Bivén, K.; Bando, H.; Ogawa, T.; Linder, S. Measurement of an apoptotic product in the sera of breast cancer patients. Eur. J. Cancer 2003, 39, 769-774. [CrossRef]

20. Linder, S.; Havelka, A.M.; Ueno, T.; Shoshan, M.C. Determining tumor apoptosis and necrosis in patient serum using cytokeratin 18 as a biomarker. Cancer Lett. 2004, 214, 1-9. [CrossRef] 
21. Bantel, H.; Lügering, A.; Heidemann, J.; Volkmann, X.; Poremba, C.; Strassburg, C.P.; Manns, M.P.; Schulze-Osthoff, K. Detection of apoptotic caspase activation in sera from patients with chronic HCV infection is associated with fibrotic liver injury. Hepatology 2004, 40, 1078-1087. [CrossRef] [PubMed]

22. Papatheodoridis, G.V.; Hadziyannis, E.; Tsochatzis, E.; Chrysanthos, N.; Georgiou, A.; Kafiri, G.; Manolakopoulos, S.; Tiniakos, D.G.; Giannousis, I.; Manesis, E.K.; et al. Serum apoptotic caspase activity as a marker of severity in HBeAg-negative chronic hepatitis B virus infection. Gut 2007, 57, 500-506. [CrossRef] [PubMed]

23. Wang, H.; Bloom, O.; Zhang, M.; Vishnubhakat, J.M.; Ombrellino, M.; Che, J.; Frazier, A.; Yang, H.; Ivanova, S.; Borovikova, L.; et al. HMG-1 as a Late Mediator of Endotoxin Lethality in Mice. Science 1999, 285, 248-251. [CrossRef] [PubMed]

24. Rovere-Querini, P.; Capobianco, A.; Scaffidi, P.; Valentinis, B.; Catalanotti, F.; Giazzon, M.; Dumitriu, I.E.; Müller-Knapp, S.; Iannacone, M.; Traversari, C.; et al. HMGB1 is an endogenous immune adjuvant released by necrotic cells. EMBO Rep. 2004, 5, 825-830. [CrossRef] [PubMed]

25. McGill, M.R. The past and present of serum aminotransferases and the future of liver injury biomarkers. EXCLI J. 2016, 15, 817-828. [CrossRef] [PubMed]

26. Karmen, A.; Wróblewski, F.; LaDue, J.S. Transaminase Activity in Human Blood. J. Clin. Investig. 1955, 34, 126-133. [CrossRef]

27. Wang, K.; Zhang, S.; Marzolf, B.; Troisch, P.; Brightman, A.; Hu, Z.; Hood, L.E.; Galas, D.J. Circulating microRNAs, potential biomarkers for drug-induced liver injury. Proc. Natl. Acad. Sci. USA 2009, 106, 4402-4407. [CrossRef]

28. Willeit, P.; Skroblin, P.; Moschen, A.R.; Yin, X.; Kaudewitz, D.; Zampetaki, A.; Barwari, T.; Whitehead, M.; Ramírez, C.M.; Goedeke, L.; et al. Circulating MicroRNA-122 Is Associated with the Risk of New-Onset Metabolic Syndrome and Type 2 Diabetes. Diabetes 2016, 66, 347-357. [CrossRef]

29. Heinemann, F.G.; Tolkach, Y.; Deng, M.; Schmidt, D.; Perner, S.; Kristiansen, G.; Müller, S.C.; Ellinger, J. Serum miR-122-5p and miR-206 expression: Non-invasive prognostic biomarkers for renal cell carcinoma. Clin. Epigenetics 2018, 10, 11. [CrossRef]

30. Umbaugh, D.S.; Jaeschke, H. Biomarkers of drug-induced liver injury: A mechanistic perspective through acetaminophen hepatotoxicity. Expert Rev. Gastroenterol. Hepatol. 2021, 15, 363-375. [CrossRef]

31. Senior, J.R. Alanine Aminotransferase: A Clinical and Regulatory Tool for Detecting Liver Injury-Past, Present, and Future. Clin. Pharmacol. Ther. 2012, 92, 332-339. [CrossRef]

32. Alfirevic, A.; Pirmohamed, M. Predictive Genetic Testing for Drug-Induced Liver Injury: Considerations of Clinical Utility. Clin. Pharmacol. Ther. 2012, 92, 376-380. [CrossRef] [PubMed]

33. McGill, M.R.; Jaeschke, H. Biomarkers of drug-induced liver injury. Adv. Pharmacol. 2019, 85, 221-239. [CrossRef]

34. Roberts, D.W.; Lee, W.M.; Hinson, J.A.; Bai, S.; Swearingen, C.J.; Stravitz, R.T.; Reuben, A.; Letzig, L.; Simpson, P.M.; Rule, J.; et al. An Immunoassay to Rapidly Measure Acetaminophen Protein Adducts Accurately Identifies Patients with Acute Liver Injury or Failure. Clin. Gastroenterol. Hepatol. 2017, 15, 555-562.e3. [CrossRef]

35. Urban, T.J.; Aithal, G.; Daly, A. Genetic Basis of Drug-Induced Liver Injury: Present and Future. Semin. Liver Dis. 2014, 34, 123-133. [CrossRef] [PubMed]

36. Hetherington, S.; McGuirk, S.; Powell, G.; Cutrell, A.; Naderer, O.; Spreen, B.; Lafon, S.; Pearce, G.; Steel, H. Hypersensitivity reactions during therapy with the nucleoside reverse transcriptase inhibitor abacavir. Clin. Ther. 2001, 23, 1603-1614. [CrossRef]

37. Reuben, A.; Tillman, H.; Fontana, R.J.; Davern, T.; McGuire, B.; Stravitz, R.T.; Durkalski, V.; Larson, A.M.; Liou, I.; Fix, O.; et al. Outcomes in Adults with Acute Liver Failure Between 1998 and 2013. Ann. Intern. Med. 2016, 164, 724-732. [CrossRef]

38. Thanapirom, K.; Treeprasertsuk, S.; Soonthornworasiri, N.; Poovorawan, K.; Chaiteerakij, R.; Komolmit, P.; Phaosawasdi, K.; Pinzani, M. The incidence, etiologies, outcomes, and predictors of mortality of acute liver failure in Thailand: A population-base study. BMC Gastroenterol. 2019, 19, 18. [CrossRef]

39. Warrillow, S.; Bailey, M.; Pilcher, D.; Kazemi, A.; McArthur, C.; Young, P.; Bellomo, R. Characteristics and outcomes of patients with acute liver failure admitted to Australian and New Zealand intensive care units. Intern. Med. J. 2019, 49, 874-885. [CrossRef]

40. De Clercq, P.; Geerts, A.; Van Vlierberghe, H.; Verhelst, X. The utility of biomarkers in prognosis assessment of patients with acute liver failure. Hepatol. Res. 2021, 51, 750-757. [CrossRef]

41. Xiao, L.-L.; Zhang, F.; Zhao, Y.-L.; Zhang, L.-J.; Xie, Z.-Y.; Huang, K.-Z.; Ouyang, X.-X.; Wu, X.-X.; Xu, X.-W.; Li, L.-J. Using advanced oxidation protein products and ischae-mia-modified albumin to monitor oxidative stress levels in patients with drug-induced liver injury. Sci. Rep. 2020, 10, 18128. [CrossRef]

42. Olson, H.; Betton, G.; Robinson, D.; Thomas, K.; Monro, A.; Kolaja, G.; Lilly, P.; Sanders, J.; Sipes, G.; Bracken, W.; et al. Concordance of the Toxicity of Pharmaceuticals in Humans and in Animals. Regul. Toxicol. Pharmacol. 2000, 32, 56-67. [CrossRef]

43. FDA; CDER. Guidance for Industry Drug-Induced Liver Injury: Premarketing Clinical Evaluation; FDA; CDER: Silver Spring, MD, USA, 2009.

44. Watkins, P.B.; Kaplowitz, N.; Slattery, J.T.; Colonese, C.R.; Colucci, S.V.; Stewart, P.W.; Harris, S.C. Aminotransferase Elevations in Healthy Adults Receiving 4 Grams of Acetaminophen Daily. JAMA 2006, 296, 87-93. [CrossRef] [PubMed]

45. Heard, K.J.; Green, J.L.; Dart, R.C. Serum Alanine Aminotransferase Elevation During 10 Days of Acetaminophen Use in Nondrinkers. Pharmacother. J. Hum. Pharmacol. Drug Ther. 2010, 30, 818-822. [CrossRef] [PubMed]

46. Heard, K.; Green, J.L.; Anderson, V.; Bucher-Bartelson, B.; Dart, R.C. A randomized, placebo-controlled trial to determine the course of aminotransferase elevation during prolonged acetaminophen administration. BMC Pharmacol. Toxicol. 2014, 15, 39. [CrossRef] 
47. Watkins, P.B.; Zimmerman, H.J.; Knapp, M.J.; I Gracon, S.; Lewis, K.W. Hepatotoxic effects of tacrine administration in patients with Alzheimer's disease. JAMA 1994, 271, 992-998. [CrossRef]

48. Gracon, S.I.; Knapp, M.J.; Berghoff, W.G.; Pierce, M.; DeJong, R.; Lobbestael, S.J.; Symons, J.; Dombey, S.L.; Luscombe, F.A.; Kraemer, D. Safety of Tacrine: Clinical Trials, Treatment IND, and Postmarketing Experience. Alzheimer Dis. Assoc. Disord. 1998, 12, 93-101. [CrossRef]

49. Harrill, A.; Roach, J.; Fier, I.; Eaddy, J.S.; Kurtz, C.L.; Antoine, D.J.; Spencer, D.M.; Kishimoto, T.K.; Pisetsky, D.S.; Park, B.K.; et al. The Effects of Heparins on the Liver: Application of Mechanistic Serum Biomarkers in a Randomized Study in Healthy Volunteers. Clin. Pharmacol. Ther. 2012, 92, 214-220. [CrossRef] [PubMed]

50. Singhal, R.; Harrill, A.H.; Menguy-Vacheron, F.; Jayyosi, Z.; Benzerdjeb, H.; Watkins, P.B. Benign elevations in serum aminotransferases and biomarkers of hepatotoxicity in healthy volunteers treated with cholestyramine. BMC Pharmacol. Toxicol. 2014, 15, 42. [CrossRef]

51. Rautou, P.-E.; Cazals-Hatem, D.; Moreau, R.; Francoz, C.; Feldmann, G.; Lebrec, D.; Ogier-Denis, E.; Bedossa, P.; Valla, D.; Durand, F. Acute Liver Cell Damage in Patients With Anorexia Nervosa: A Possible Role of Starvation-Induced Hepatocyte Autophagy. Gastroenterology 2008, 135, 840-848.e3. [CrossRef] [PubMed]

52. Vazquez, J.H.; Clemens, M.M.; Allard, F.D.; Yee, E.U.; Kennon-McGill, S.; Mackintosh, S.G.; Jaeschke, H.; Hambuchen, M.D.; McGill, M.R. Identification of Serum Biomarkers to Distinguish Hazardous and Benign Aminotransferase Elevations. Toxicol. Sci. 2020, 173, 244-254. [CrossRef] [PubMed]

53. Mcburney, R.N.; Hines, W.M.; Von Tungeln, L.S.; Schnackenberg, L.K.; Beger, R.D.; Moland, C.L.; Han, T.; Fuscoe, J.C.; Chang, C.-W.; Chen, J.J.; et al. The Liver Toxicity Biomarker Study: Phase I Design and Preliminary Results. Toxicol. Pathol. 2009, 37, 52-64. [CrossRef] [PubMed]

54. McBurney, R.N.; Hines, W.M.; VonTungeln, L.S.; Schnackenberg, L.K.; Beger, R.D.; Moland, C.L.; Han, T.; Fuscoe, J.C.; Chang, C.-W.; Chen, J.J.; et al. The Liver Toxicity Biomarker Study Phase I: Markers for the Effects of Tolcapone or Entacapone. Toxicol. Pathol. 2012, 40, 951-964. [CrossRef] [PubMed] 